\title{
Relationship between Quality of the Referral Chain of Hospital Services and Patient Satisfaction
}

\author{
Farzaneh Mahmoudi Meymand ${ }^{1}$, Aidin Aryankhesal ${ }^{1,2}$ \& Pouran Raeissi ${ }^{1}$ \\ ${ }^{1}$ Department of Health Services Management, School of Health Management and Information Sciences, Iran \\ University of Medical Sciences, Tehran, Iran \\ ${ }^{2}$ Health Management and Economics Research Center, Iran University of Medical Sciences, Tehran, Iran \\ Correspondence: Aidin Aryankhesal, Department of Health Services Management, School of Health \\ Management and Information Sciences, Iran University of Medical Sciences, Tehran, Iran. Tel: 98-218-877-3073. \\ E-mail: aryankhesal.a@iums.ac.ir
}

Received: March 6, 2016 Accepted: May 18, 2016 Online Published: June 30, 2016

doi:10.5539/gjhs.v9n2p68 URL: http://dx.doi.org/10.5539/gjhs.v9n2p68

\begin{abstract}
Introduction: The aim of this study was to examine the relationship between quality of the referral chain of hospital services and patient satisfaction in Kerman, Iran.

Methods: The study was quantitative-qualitative and crosses-sectional, conducted during August-October, 2015 in a hospital in Kerman, Iran. Two questionnaires were used in the study. During data collection, 115 patients were referred from a public hospital to an imaging center for imaging services that quality of the referral chain and satisfaction were studied. The quality of referral change was completed by the head nurses of the hospital. Satisfaction from referral service was assessed by the patient. In order to investigate the correlation between patient satisfaction and the supply chain quality and its domains the Pearson correlation test was conducted.
\end{abstract}

Findings: The average score of quality of the referral chain was 4.53 out of 5 with a standard deviation of 0.45 . The average score of patient satisfaction from the referred services was 4.12 out of 5 , with a standard deviation of 0.52. "Provision of information to patients" got the highest average and "effective communication" the least among the dimensions of quality of the referral chain. There was a significant relationship between the quality of referral chain and patient satisfaction from the referred services.

Conclusion: Participation of all suppliers in the supply chain can create an atmosphere of sincere cooperation between the organizations. Long-term plans should be established to set cooperation among supply chain parties, i.e. hospitals and satellite labs and imaging centers.

Keywords: quality of care, referral chain, patient satisfaction, Iran

\section{Introduction}

The recent healthcare reform in Iran aimed at improving the quality of services and patient satisfaction through three main strategies (i) financial protection for people, (ii) equality in access to health services, and (iii) procedure improvement initiatives (Ministry of Health and Medical Education, 2014).

One of the main issues to solve through the reform was to reduce and eventually eliminate sending patients out of hospitals for purchasing or receiving the lacking medicine, medical instruments or diagnostic services. Therefore all hospitals were required to provide patients with all diagnostic and therapeutic services as far as the items were covered by the basic health insurance organizations. Alternatively, if hospitals lack any item, they should facilitate the "referral chain" or "supply chain", by which all necessary items should be ordered for patients by hospitals or patients are just sent to other centers for diagnostic services and consultation at the hospital's expense (Ministry of Health and Medical Education, 2014). The necessity of implementation of referral chain is even more important for board of trustees - operated hospitals (Markazi-Moghaddam et al., 2014).

Supply chain is created and used with the aim of improvement and competitiveness of quality of service, customer satisfaction and ultimately increasing profitability and reducing costs. Although cross-sectorial coordination in a supply chain is difficult to apply, long-term relationship has always been an important part of 
the continuum (Azar \& Mohamadlu, 2010; Mentzer et al., 2001).

In fact, efforts to optimize organizational processes regardless of suppliers and customers seem useless and organizations that are working together for common goals appear to have a better performance (Hoseini \& Sheykhi, 2012). When managers try to make an individual decision in one part of the supply chain such as procurement, production or distribution should note that the chosen solution will also optimize the entire supply chain with an emphasis on maximizing the total value of the chain (Stanley \& Wisner, 2001; Samuel et al., 2010).

Several studies have been conducted in the field of supply chain services, but the subject of customer satisfaction has rarely been discussed in the health sector.

Matthew and his colleagues in their studies emphasized that timely delivery and accountability to costumer are the main goals of the chain and at the conclusion of their investigation state the health care industry are very interdependent to each other and one sector cannot ensure the total efficiency (Mathew et al., 2013).

Other studies have considered the integration of the supply chain as one of the biggest challenges of the organizations that are involved in health care (Kitsiou et al., 2007; Tutuncu \& Kucukusta, 2008). In another study the patient satisfaction, as a criterion for achieving the organization goals and missions, is presented and it involves a level of people's perception of the quality, efficiency, effectiveness, cooperation and good faith (Swinehart \& Smith, 2005).

In a study entitled "The role of supply chain management integration in quality management system for hospitals", the hospital integration with internal and external customers is known to be an important factor in implementing and strengthening the overall integration process in hospital quality management system (Tutuncu \& Kucukusta, 2008).

According to Stanley research entitled "Service quality along the supply chain: implications for purchasing", the aspects which are considered as an important scale to assess the performance of supply chain quality or referral are:

1. Quality of products/services received,

2. Responding to the needs of internal customers,

3. Flexibility to the changing needs of domestic customers,

4. Timely delivery of goods,

5. The ability to meet the expectations of local customers,

6. Provide information on delivery times,

7. Reliability of the information provided,

8. Explanation of the problem,

9. Effective Communication (Stanley \& Wisner, 2001).

Considering the importance of the supply chain in the function of hospitals and the new law of supply chain in the reformation plan in the health care system, and also the lack of studies on how to manage the hospital and its supply chain with the ultimate goal of improving reformation plan in this area, i.e. patient satisfaction, this study is an attempt to investigate the quality of the implementation supply chain services and its relationship to patient satisfaction in hospitals.

\section{Method}

The study was quantitative-qualitative and crosses-sectional and was done during August, September and October, 2015. The environment study was Shafa teaching hospital (affiliated to Kerman University of Medical Sciences). In fact, for a deeper consideration of the subject, only one hospital was selected. In other words, the research was a case study (Yin, 2008).

Research society was hospital referral services and tools for collecting data were questionnaires. Two questionnaires were used in this study:

1. The questionnaire contains 19 questions that evaluate the quality of the supply chain for each service. There are five options on 5 aspects including communication, accountability, providing information, Explanation of the problem and the quality of products/services received, and an open question. 2 . The questionnaire contains 15 questions on referred patient satisfaction with five options and 4 open questions. 
To design quality supply chain questionnaire firstly, based primarily on studies that had been done in the field, the supply chain quality dimensions were identified (Stanley \& Wisner, 2001; Ajam et al., 2013; Chu-Hua \& Madu, 2001; Azar \& Mohamadlu, 2010; Hashjin et al., 2014; Kuei \& Madu, 2001; Schneller, 2000; Stank et al., 2005; Power, 2005; Chen et al., 2013) and then given to the specialists in this field to prove its validity. In order to measure patient satisfaction on received services, the designed Questionnaire in the Assessment of health reform system in the field of treatment in September 2014 was used (Ministry of Health and Medical Education, 2014) and according to the research goals, the items were adjusted, the study data were collected based on the Likert scale was arranged (5 options), and open questions. In this research to ensure the validity of the questionnaire were used experts 'view point. Reliability or stability of quality and satisfaction questionnaires was measured with Cronbach's alpha coefficient. Due to time limitation, lack of registered information and the need to collect data, three months were allocated to collect data. During this time 115 referred imaging services were studied, and in turn for each service, a quality service questionnaire regarding referral chain and a referred patient satisfaction questionnaire were filled out.

Quality questionnaire referral was completed by the head nurses of the referral supply chain; so that at the end of each day, referred services were identified by contacting the nurses' offices and about the service, supply chain quality was assessed with reference to the head of referral unit. Satisfaction of referral service was assessed by the patient so that the patient who was sent to another hospital for a service, an appointment was made and after that the questionnaire responses were collected. If the patient was discharged from the hospital and did not return; calls were made to measure the satisfaction.

After collecting data, closed question questionnaire using descriptive and inferential statistics were analysed. To investigate the correlation between patient satisfaction and the supply chain quality; the aspects of the questionnaire related to each service were analysed in the form of paired and Pearson correlation test at the level of 5 per cent error. Open questions answers related to the implementation obstacles of the referral supply chain were classified after coding and content analysis as descriptive (Merriam, 2009).

\section{Results}

The demographic characteristics of the patients participating in the study are summarized at Table 1.

Table 1. Demographic characteristics of the care receivers

\begin{tabular}{llll}
\hline Demographic variables & & Frequency & Percent \\
\hline \multirow{4}{*}{ Age } & Less than 19 & 2 & 1.7 \\
& $29-20$ & 16 & 13.9 \\
& $39-30$ & 14 & 12.2 \\
& $49-40$ & 23 & 20.0 \\
Gender & $59-50$ & 18 & 15.7 \\
& More than 60 & 39 & 33.9 \\
& Male & 63 & 54.8 \\
Education & Female & 52 & 45.2 \\
& Illiterate & 48.7 \\
& Secondary education & 56 & 29.6 \\
& College degree & 34 & 11.3 \\
Insurance & Bachelor of science & 13 & 7.8 \\
& Masters of science & 9 & 2.6 \\
& PhD & 3 & 49.6 \\
Supplementary insurance & Health care service & 57 & 38.3 \\
& Social welfare & 44 & 4.3 \\
& The armed forces & 5 & 2.6 \\
& Other insurances & 3 & 5.2 \\
& Uninsured & 6 & 30.91 \\
& Yes & 34 & 69.09 \\
\hline
\end{tabular}


In this study the quality of products/services received, responding to the needs of patients referred, providing information, description of the problem and effective communication are aspects that were considered for assessing the quality of supply chain services in the hospital.

The average of quality score was 4.53 out of 5 with a standard deviation of .45 . The mean scores for each of the quality of the supply chain are in Table 2 .

Table 2. Mean and the standard deviation for each dimension of supply chain quality

\begin{tabular}{lll}
\hline Dimension of supply chain quality & Mean & Standard deviation \\
\hline Quality of products/services received & 4.46 & .29 \\
Responding to the needs of referred patients & 4.50 & .47 \\
Providing information & 4.82 & .35 \\
Explanation of the problem & 4.55 & .61 \\
Effective Communication & 4.30 & 1.52 \\
\hline
\end{tabular}

According to Table 2, providing information with the highest average standard deviation of 0.35 and then effective communication with an average of 4.30 out of 5 score and a standard deviation of 1.52 is the lowest average among the dimensions of quality measurement.

In assessing the patient satisfaction of hospital referral chain, the men's average score was 4.17 and women's average score was 4.07 out of 5 and standard deviation were 0.48 and 0.56 , respectively. Given that the amount of $\mathrm{p}$ is more than 0.05 , it can be concluded there is no significant relationship between sex and satisfaction. (T-test Test, $p$-value $=0.11$ ) and also, according to the correlation test there is no significant relationship between satisfaction and age, $\mathrm{p}$-value $=0.22$.

Table 3. Average satisfaction scores according to the type of insurance

\begin{tabular}{lll}
\hline Type of insurance & Mean & Standard deviation \\
\hline Health care service & 4.11 & .56 \\
Social welfare & 4.12 & .49 \\
The armed forces & 4.02 & .60 \\
Other insurances & 4.18 & .50 \\
Uninsured & 4.38 & .17 \\
Total & 4.13 & .52 \\
\hline
\end{tabular}

In this study, the most and least satisfaction is related to the uninsured and the armed forces. As Table 3 shows, this difference makes no sense and according to ANOVA test, there is no significant relationship between satisfaction and insurance, $p$-value $=0.79$ (more than 0.05).

The average satisfaction score of those who had supplementary insurance was 4.03 with a standard deviation of 0.59 and for those who did not have supplementary insurance was 0.48 with a standard deviation7.18. Based on statistical analysis, T-test, there was no significant relationship between satisfaction and supplementary insurance, $\mathrm{P}$-value $=0.105$.

Table 4. Average satisfaction scores based on education

\begin{tabular}{lll}
\hline Education & Mean & Std. Deviation \\
\hline Illiterate & 4.26 & .43 \\
Secondary education & 4.03 & .57 \\
College degree & 3.74 & .57 \\
Bachelor of science & 4.31 & .33 \\
Masters of science and above & 3.78 & .67 \\
Total & 4.13 & .52 \\
\hline
\end{tabular}


According to Table 4, the highest average satisfaction from hospital services in the supply chain were related to Bachelor of Science and college degrees were in the least amount of satisfaction and also, according to ANOVA test there was a significant relationship between satisfaction and education which needs further studies $\mathrm{p}$-Value $=0.004$.

The assessment of relationship between supply chain quality of hospital services with satisfaction:

In this study, between the total satisfaction average and all aspects of supply chain quality of hospital services (quality of products/services received, Responding to the needs of referred patients, Providing information, Explanation of the problem and Effective communications) There is a significant relationship.

The findings related to the correlation between the quality of the supply chain and patient satisfaction are presented in Table 5 .

According to the correlation between the average satisfaction and the total quality supply chain services, there is a significant relationship. Results show with an increase in the quality of supply chain services, satisfaction is increased $\left(\mathrm{P}-\right.$ value $\leqslant 0.0001 ; 388^{* *}=$ Pearson Correlation $)$.

Table 5.Correlation between the dimensions of supply chain quality and patient satisfaction

\begin{tabular}{lll}
\hline $\begin{array}{l}\text { Correlation between the dimensions of supply chain quality and patient } \\
\text { satisfaction }\end{array}$ & P-value & $\begin{array}{l}\text { The correlation } \\
\text { coefficient }\end{array}$ \\
\hline Quality of products/services received & 0.003 & .275 \\
Responding to the needs of referred patients & $\leq 0.0001$ & .484 \\
Providing information & $\leq 0.0001$ & .458 \\
Explanation of the problem & 0.02 & .217 \\
Effective Communication & 0.046 & .186 \\
Total quality & $\leq 0.0001$ & .388 \\
\hline
\end{tabular}

The supply chain program in the Hospital has strengths and weaknesses. The items that have been identified in this study are shown in the Table 6.

Table 6. Issues identified in relation to the supply chain of hospital services

\begin{tabular}{ll}
\hline Weak points & Strength points \\
\hline - Problems of coordination & \\
- Delay in ambulance dispatch & $\begin{array}{l}\text { - All respondents confirmed that the origin hospital has } \\
\text { provided ambulance }\end{array}$ \\
- Delay in providing solutions by specialists & $\begin{array}{l}\text { - All respondents confirmed that no fees were received } \\
\text { - Lack of some facilities for patients (food, ...) }\end{array}$ \\
$\begin{array}{ll}\text { - lack of private rooms } & \text { - The satisfaction from the service provider's staff in the } \\
\text { - Patient dissatisfaction with the lack of adequate } \\
\text { explanations about the disease and how to control it }\end{array}$ & $\begin{array}{l}\text { origin hospital } \\
\text { - Lack of respectful treatment at the target clinic }\end{array}$ \\
\hline
\end{tabular}

\section{Discussion}

The aim of this study was to determine the relationship between the quality of hospital services and patient satisfaction in hospital referral chain in Kerman and review the strengths and weaknesses of the referral chain. Pearson correlation showed that there is a significant relationship between the quality of the supply chain with patient consent, and with an increase of the service quality the patient satisfaction of received services in referral chain increases.

The Safari's results showed that, both focus on the customer and supplier quality management are the most important factors in the implementation of quality management of the supply chain and emphasize that organizations and companies should then, prior to any actions identify current and future needs of its customers correctly and invest in the quality from customers 'viewpoint (Safari \& Mohebimanesh, 2011).

Swinehart KD and Smith AE brought in their study that customer satisfaction is increasingly known as a measure 
for determining a good organization to fulfill its mission (Swinehart \& Smith, 2005).

Dalvi and his colleagues believe that a supply chain must be efficient, responsive, flexible and particularly, integrated to lead to improved performance of the organization. Supply chain partners must share the information and responsibilities must be defined. The organization structure must be designed in a way that results in the decrease of the hierarchy, bureaucracy, and waste administrative rules and the increase of flexibility in the organization structure, a high coordination among department on the other hand. And also the flow of information must be done easily and quickly (DalviEsfahani et al., 2013).

Robinson and Malhotra, with a comprehensive review of literature in the field of supply chain management and quality management, presented in the classification of different dimensions from the perspective of supply chain the following cases: 1) participation and communication with customers and suppliers 2) integration and process management throughout the chain 3) leadership and management of quality in chains 4) Strategy 5) best practices (Robinson \& Malhotra, 2005).

The findings of the study " Service quality along the supply chain: implications for purchasing " showed strong positive relationship between the execution of buy/suppliers, the quality of service provided to internal and external customer service and product quality )Stanley \& Wisner, 2001(.

Enhance competitiveness, government regulations, Increasing costs, demand for higher quality of service are impressed Health providers., healthcare becomes a complex activity to manage Various locations, changing organizational structures, Integration, employees, and multiple information systems Around the World. Healthcare organizations must try to added value in the whole supply chain by monitoring supply chain performance (Mathew et al., 2013).

According to de Vries's study most author have emphasized supply chain management in a Health structure is identified by Unique characteristics, which make it hard to transfer of knowledge from the manufacturing sector to a health sector in a Specified path. It can be interpreted that existing Perception, models and supply chain procedure can be expanded to supply chain management in health sector and the health sector can Profit from the lessons learned in the industrial sector. Obviously, Measure the performance of health care sector seems to be more Complex compared to industry companies Because of the complexity of views such as "quality of care" (de Vries \& Huijsman, 2011).

Supply chain policies with regard to product demand, diversification, unit cost, physical size, and sensitivity is different. This distinction hospital supply chain with strategy to maximize patient care is highly desirable (DeScioli, 2005).

According to Swinehart and Smith study Customer satisfaction is being known as an appropriate action for determining how well an organization is accomplishing its mission. Perceived levels of quality, effectiveness, and efficiency, courtesy and cooperation measures are important determinants of organizational success (Swinehart \& Smith, 2005).

In this study, the majority of the items listed in the above studies were included in the quality dimensions questionnaire and for each of the dimensions of quality (quality of products/services received, Responding to the needs of referred patients, Providing information, Explanation of the problem and Effective communications), average score of 4 out of 5 was achieved and this shows the quality and acceptability of the supply chain.

According to research carried out, two major problems of the supply chain, the uncertainty and the need for coordination between the various activities. The most important factors that supply chain management has difficulty with the human factor. Structurally most important problem with which the supply chain is dealing with is facing a number of difficult decision-making centers. Another of the problem that exist in the supply chain is knowledge a symmetry between the components of the supply chain that, under investigation, leads to low efficiency of the chain (Rajabzadeh et al., 2007).

And Kabossa A.B. Msimang Ira study has identified three important barriers to ensure the integrity of the supply chain: the reluctance to share information, problems with relationships based on shared risks and rewards, and inadequate information systems. This study has identified the problems such as uncertainty and the need for coordination, information asymmetry, and problems related to information systems and hospital referral chain during the implementation of the program (Fawcett et al., 2007).

\section{Conclusion}

It can be said that there is no agreement between the assessing dimensions of supply chain management operations. In fact, the researchers based their studies on specific criteria and according to their search criteria 
examined the variable impact of supply chain management operations on the company's performance (Hoseini \& Sheykhi, 2012). Basically, adherence to the four principles of human resources, organizational structure, information technology and informing at the same time guarantees success and the excellence of supply chain achievement.

Equal treatment between customers and suppliers (consistency), sharing information with all levels of the supply chain, cooperation and coordination throughout the supply chain, having clear objectives and realistic expectations for all of the facts surrounding supply chain, integrating activities in the supply chain processes, creating partnerships based on mutual trust and confidence, dividing profit or loss for both sides, reducing response time across the supply chain, the use of different suppliers (outsourcing), providing quality goods or services, providing goods or services intended in due time, the flexibility to change supply and demand for goods or services, the effective use of information systems to transmit supply chain information, sharing knowledge and technology are listed among the most effective factors in the success of the supply chain (Rajabzadeh et al., 2007).

It is believed that the supply chain in the health care is inherently complex and therefore finding a magic key to remove inefficiencies and incompetence, and ultimately help to reduce costs will be very difficult.

The current trend indicates that the industry is trying to deliver goods and services on time. The major drawback is in the fact that if every part of the supply chain works independently, varying activities will prevent it from being considered as a system .Organizations must be responsive to the needs of customers and other stakeholders and also their satisfaction; motivation to integrate supply chain is strongly and it follows tremendous potential benefits (Fawcett et al., 2007).

This research suggests the participation of all suppliers in the supply chain planning process to create an atmosphere of sincere cooperation between the organizations involved, long-term plans to communicate with the parts of supply chain, establishing appropriate information systems and the provision of adequate resources in the field of health (including manpower, equipment and ambulance, etc.) for having a dynamic supply chain system.

\section{Acknowledgments}

This study was part of a M.S. dissertation, supported and sponsored by Iran University of Medical Sciences.

\section{Competing Interests Statement}

The authors declare that there is no conflict of interests regarding the publication of this paper.

\section{References}

Ajam, M., Far, J. S., \& Anjomshoa, M. (2013). Quality of health services using SERVQUAL model: Case of a field hospital. Journal of Military Medicine, 15, 273-79. [Persian]

Azar, A., \& Mohamadlu, M. (2010). Designing service quality in the supply chain, explain the concept of quality interactive services. Prospects Business Administration, 23-41. [Persian]

Chen, D. Q., Preston, D. S., \& Xia, W. (2013). Enhancing hospital supply chain performance: A relational view and empirical test. Journal of Operations Management, 31, 391-408. http://dx.doi.org/10.1016/j.jom. 2013.07.012

Chu-Hua, K., \& Madu, C. N. (2001). Identifying critical success factors for supply chain quality management (SCQM). Asia Pacific Managemenl Review, 6, 409-23.

Dalviesfahani, M. R., Gorbani, H., \& Galehsalimi, M. B. (2013). The Study of Effect Marketing Strategies Alignment on Supply Chain and Organizational Performance (Case: Entekhab Industrial Group). Marketing Management. [Persian]

De Vries, J., \& Huijsman, R. (2011). Supply chain management in health services: An overview. Supply Chain Management: An International Journal, 16, 159-65. http://dx.doi.org/10.1108/13598541111127146

Descioli, D. T. (2005). Differentiating the hospital supply chain for enhanced performance. Citeseer.

Fawcett, S. E., Magnan, G. M., \& Ogden, J. (2007). Achieving world-class supply chain collaboration: Managing the transformation. Institute for Supply Management, Tempe, AZ.

Hashjin, A. A., Kringos, D. S., Manoochehri, J., Aryankhesal, A., \& Klazinga, N. S. (2014). Development and impact of the Iranian hospital performance measurement program. BMC health services research, $14,1$. http://dx.doi.org/10.1186/1472-6963-14-448 
Hoseini, M., \& Sheykhi, N. (2012). Explain the role strategic supply chain management operations to improve company performance: The food industry in Iran. Strategic Management Studies, 35-60. [Persian]

Kitsiou, S., Matopoulos, A., Manthou, V., \& Vlachopoulou, M. (2007). Evaluation of integration technology approaches in the healthcare supply chain. International Journal of Value Chain Management, 1, 325-43. http://dx.doi.org/10.1504/IJVCM.2007.015091

Kuei, C.-H., \& Madu, C. N. (2001). Identifying critical success factors for supply chain quality management (SCQM). Asia Pacific Management Review, 6, 409-23.

Markazi-Moghaddam, N., Aryankhesal, A., \& Arab, M. (2014). The first stages of liberalization of public hospitals in Iran: Establishment of autonomous hospitals and the barriers. Iranian Journal of Public Health, 43, 1640-50.

Mathew, J., John, J., \& Kumar, S. (2013). New Trends in Healthcare Supply chain. POMS 24th Annual Conference "Integrating Practice in POM Research and Teaching" May.

Mentzer, J. T., Flint, D. J., \& Hult, T. M. (2001). Logistics Service Quality as a Segment-Customized Process. Journal of Marketing, 65, 82-104. http://dx.doi.org/10.1509/jmkg.65.4.82.18390

Merriam, S. B. (2009). Qualitative Research: A Guide to Design and Implementation. San Francisco Jossey-Bass.

Ministry of Health and Medical Education. (2014). Assessment of health reform system in the field of treatment. Tehran.

Power, D. (2005). Supply chain management integration and implementation: A literature review. Supply chain management: An International Journal, 10, 252-63. http://dx.doi.org/10.1108/13598540510612721

Rajabzadeh, A., Khadivar, A., \& Kazemi, A. (2007). The effect of the supply chain to improve the quality of customer service and develop the main components. Journal of Research Commerce, 185-223. [Persian]

Robinson, C. J., \& Malhotra, M. K. (2005). Defining the concept of supply chain quality management and its relevance to academic and industrial practice. International Journal of Production Economics, 315-37. http://dx.doi.org/10.1016/j.ijpe.2004.06.055

Safari, H., \& Mohebimanesh, O. (2011). Providing a conceptual model to evaluate the supply chain and quality management in the automotive industry of Iran (Case study: Project 90 Thunder Iran Khodro Company). Industrial Management, 3, 77-98. [Persian]

Samuel, C., Gonapa, K., Chaudhary, P., \& Mishra, A. (2010). Supply chain dynamics in healthcare services. International Journal of Health Care Quality Assurance, 23, 631-42. http://dx.doi.org/10.1108/095268 61011071562

Schneller, E. S. (2000). The value of group purchasing in the health care supply chain. School of Health Administration and Policy. Arizona State University College of Business, Tempe.

Stank, T. P., Davis, B. R., \& Fugate, B. S. (2005). A strategic framework for supply chain oriented logistics. Journal of Business Logistics, 26, 27-46. http://dx.doi.org/10.1002/j.2158-1592.2005.tb00204.x

Stanley, L. L., \& Wisner, J. D. (2001). Service quality along the supply chain: Implications for purchasing. Journal of Operations Management, 287-306. http://dx.doi.org/10.1016/S0272-6963(00)00052-8

Swinehart, K. D., \& Smith, A. E. (2005). Internal supply chain performance measurement: A health care continuous improvement implementation. International Journal of Health Care Quality Assurance, 18, 533-42. http://dx.doi.org/10.1108/09526860510627210

Tutuncu, O., \& Kucukusta, D. (2008). The role of supply chain management integration in quality management system for hospitals. International Journal of Management Perspectives, 1, 31-39.

Yin, R. K. (2008). Case Study Research: Design and Methods. SAGE Publications, Inc.

\section{Copyrights}

Copyright for this article is retained by the author(s), with first publication rights granted to the journal.

This is an open-access article distributed under the terms and conditions of the Creative Commons Attribution license (http://creativecommons.org/licenses/by/3.0/). 